\title{
Four-year health trajectories of children prenatally exposed to cocaine and/or cannabis. A retrospective, cohort study in La Pampa, Argentina
}

\author{
Marina Villarreal, Magister and M.D. ${ }^{a, b}$, Valeria Belmonte, Magister ${ }^{b}$, \\ Agustina Abdala, M.D. ${ }^{a}$ and Jorge L. Olivares, M.D. ${ }^{a, b}$
}

\begin{abstract}
Cocaine and / or cannabis use during pregnancy is a growing problem of relevance for global public health. Exposed children may have a wide range of perinatal complications, but there is little knowledge on their course.

Objective: To describe and compare the health trajectories of children prenatally exposed and unexposed to cocaine and/or cannabis over 4 years.

Methods: Retrospective, cohort study with a double control group. Exposed children were detected through a urine test by the Department of Neonatology of a public hospital between 2009 and 2013.
\end{abstract}

Results: A total of 29 exposed children and 58 unexposed children were assessed. The most common drugs detected in the exposed group were cocaine and cannabis. Most mothers were poly-drug users. The exposed group showed significant differences in relation to a lower frequency of health checkups $(p<0.0001)$ and a higher number of visits to the emergency department $(p=0.0295)$ and hospitalizations ( $p=0.007)$, mainly due to respiratory conditions. In addition, they had a greater rate of chronic obstructive pulmonary disease, changes of home, and legal interventions. In this group, 1 child and 2 parents had a violent death. No deaths were reported in the unexposed group.

Conclusions: Children prenatally exposed to cocaine and / or cannabis had a lower number of health checkups and a higher number of visits to the emergency department and hospitalizations. Besides, they showed a greater rate of chronic obstructive pulmonary disease, changes of home, legal interventions, and violent deaths in the direct family group.

Key words: late effects of prenatal exposure, cocaine, cannabis, follow-up, morbidity and mortality.

http: / / dx.doi.org/10.5546/ aap.2019.eng.360

To cite: Villarreal M, Belmonte V, Abdala A, Olivares L. Four-year health trajectories of children prenatally exposed to cocaine and / or cannabis. A retrospective, cohort study in La Pampa, Argentina. Arch Argent Pediatr 2019;117(6):360-367.

\section{INTRODUCTION}

In most countries worldwide, the current cannabis and cocaine use during pregnancy has increased, with poly-drug use being the most common pattern. ${ }^{1-8}$

At the Department of Neonatology of the public hospital where this study was conducted, cocaine and cannabis were the most common drugs detected since 2009, when postpartum urine drug tests were first used. ${ }^{6}$

Generally speaking, children prenatally exposed to cannabis and/ or cocaine may have a wide range of complications, studied mainly during the perinatal period. ${ }^{2,4,9-19}$ Short- and long-term adverse effects have been described during childhood, some of which have been especially corroborated in relation to neurodevelopment. ${ }^{12-16}$

The bibliography offers little information about the health trajectories of these children. In a Chilean study, 100 children prenatally exposed to cocaine and other drugs missed checkups and tests and were hospitalized frequently. ${ }^{18}$

It has been described that children with exposure to drugs in utero had a greater number of visits to the hospital due to injuries compatible with abuse and negligence compared to children in the general population, with a higher percentage of social services and / or legal interventions. In most cases, biological parents had been the abusers, and this was the main cause of early or temporary removal of children from their home. $8,9,13,18,19$

In addition to the mentioned morbidity, some authors have described a greater mortality among children exposed in utero than among 
unexposed ones, but only when cocaine and opioids were used, and when the birth weight was below $2500 \mathrm{~g}^{20}$

The study objectives were to describe and analyze registered contacts with the health system in the first 4 years of life of children prenatally exposed to cocaine and / or cannabis and compare them to unexposed children. The secondary objective was to describe diseases, family/legal situation, and mortality of children or their direct family.

\section{POPULATION AND METHODS}

\section{Retrospective, cohort study}

Exposed children (exposed group [EG]): children born between 2009 and 2013 at the Department of Neonatology of EstablecimientoAsistencial Dr. LucioMolas, in the province of La Pampa, for whom cocaine and/or cannabis were detected in a post-partum urine sample (from the mother and/or the baby). The sample was requested if detection criteria were observed (Table 1).

Unexposed children (control group): children without detection criteria, born at the same Department of Neonatology on the same day or week as exposed ones. Two investigators reviewed birth records until finding the newborn infants that were most similar to each exposed baby, taking into consideration, in order of priority, maternal age, birth weight, gestational age, social security status, and place of origin.

Two unexposed children were selected for each exposed one to increase the study power. No exclusion criteria were defined.

The study outcome measures were obtained from the following secondary sources (both were used for some):

- The Health Information System (Sistema Informático de Salud, SIS) of the province of La Pampa: socioeconomic data, medical consultations, immunizations, hospitalizations, and diseases. This database included demographic data and a brief medical record of patients seen in all public health facilities of La Pampa. Diagnoses were registered as per the International Classification of Diseases (ICD-10).

- The hospital's medical records: socioeconomic, perinatal, and obstetric data, family/legal situation, hospitalizations, diseases, death of the child and/or a close family member. Hospital Molas is the leading tertiary care, referral public hospital of Santa Rosa and is one of the few provincial health facilities that had an active pediatric department, specialties, and emergency department.

The study was carried out between June 2017 and June 2018. Every week, 2 investigators collected children data from the SIS and other 2 reviewed the medical records (20 patients per month), and they completed an anonymous database specially designed for the study.

The study was approved by the Research Ethics Committee of Hospital Molas. Confidentiality was maintained by coding and limiting the study database search, recording, analysis, and access to the 4 authors/investigators. The patients' initials, names or other identifying data were not recorded.

Excel 4.0 (Microsoft Office) was used for data entry, initial processing, and graphic representations. The InfoStat software (Universidad de Córdoba) was used for statistical analysis. Children's characteristics were established based on absolute and relative frequency for qualitative outcome measures, and measures of centralization, dispersion and confidence intervals for quantitative outcome measures. The $\chi^{2}$ test, Student's t test, and proportions test were used for comparative analyses. A $p$ value $<0.05$ was considered statistically significant.

\section{RESULTS}

The EG included 29 children, while the unexposed group (UG), 58. In the EG, 16 children (55\%) were males and, in the UG, 34 (59\%).

TABLE 1. Screening criteria to perform a urine test for illegal drugs. Department of Neonatology, Hospital Molas, La Pampa. 2009-2018

1. Statement reporting current or past drug use.

2. Altered mental status in the mother.

3. Lack of antenatal care.

4. Unexplained central nervous system complications in the newborn infant.

5. Symptoms compatible with drug withdrawal in the newborn infant.

6. Changes in neonatal behavior. 
Group comparisons by selection variables are described in Table 2, which shows that both groups were homogeneous.

In both groups, more than $95 \%$ of mothers lived in the Santa Rosa-Toay geographical cluster, in the province of La Pampa. All patients were born at the same public hospital and did not have health insurance.

In the EG, the drugs detected in the urine samples from the mother and/or the baby were cocaine only in $9(31 \%)$, tetrahydrocannabinol only in $10(35 \%)$, cocaine and tetrahydrocannabinol in $5(17 \%)$, cocaine and phencyclidine and / or benzodiazepine in $5(17 \%)$.

Most mothers of children in the EG had been poly-drug users during pregnancy. In addition to the drugs detected in urine, they admitted to have used alcohol (55\%) and/or tobacco (93\%).
None of the mothers in the UG had used alcohol, whereas $21 \%$ had smoked tobacco. Significant differences $(p<0.0001)$ were observed between both groups in relation to substance use.

Table 3 shows the socioeconomic, family, and obstetric data of children's mothers. Perinatal outcomes are described in Table 4.

Upon discharge from the neonatology unit, no baby in the EG had any disease, whereas 2 babies in the UG had acyanotic congenital heart disease without medication requirements. No patient was lost-to-follow-up in the 4-year study period.

\section{Medical consultations, immunizations and hospitalizations}

Children in the EG attended less health checkups but had more visits to the emergency department than children in the UG (Table 5).

TABLE 2. Comparison between the exposed and unexposed groups based on selection variables. Children born at Hospital Molas, La Pampa, between 2009 and 2013

\begin{tabular}{lcccc}
\hline & & $\begin{array}{c}\text { Exposed group } \\
(\mathbf{n}=\mathbf{2 9 )}\end{array}$ & $\begin{array}{c}\text { Unexposed group } \\
(\mathbf{n}=\mathbf{5 8})\end{array}$ & $\begin{array}{c}\text { Comparison } \\
\text { between groups }\end{array}$ \\
\hline Birth weight (grams) & Mean (SD) & $3132(670)$ & $3355(444)$ & \\
Gestational age (weeks) & $95 \%$ CI & $2877-3387$ & $3265-3446$ & $p=0.10$ \\
Maternal age (years old) & Mean (SD) & $39(2)$ & $39(1)$ & $p=0.25$ \\
& $95 \%$ CI & $38-39$ & $39-40$ & \\
& Mean (SD) & $22(5)$ & $22(4)$ & $p=0.64$ \\
\hline
\end{tabular}

SD: standard deviation; CI: confidence interval.

TABLE 3. Socioeconomic, family, and obstetric data of the mothers of study children born at Hospital Molas between 2009 and 2013

\begin{tabular}{|c|c|c|c|c|}
\hline Education & \multicolumn{2}{|c|}{ Exposed group $(n=29)$} & \multicolumn{2}{|c|}{ Unexposed group $(n=58)$} \\
\hline $\begin{array}{l}\text { Education } \\
\text { Incomplete primary education } \\
\text { Complete primary education } \\
\text { Incomplete secondary education } \\
\text { Complete secondary education } \\
\text { Incomplete tertiary/university education }\end{array}$ & $\begin{array}{c}0 \\
10 \\
17 \\
2 \\
0\end{array}$ & $\begin{array}{l}(0 \%) \\
(34 \%) \\
(59 \%) \\
(7 \%) \\
(0 \%)\end{array}$ & $\begin{array}{c}1 \\
13 \\
33 \\
8 \\
3\end{array}$ & $\begin{array}{l}(2 \%) \\
(22 \%) \\
(57 \%) \\
(14 \%) \\
(5 \%)\end{array}$ \\
\hline $\begin{array}{l}\text { Occupation } \\
\text { Housewife } \\
\text { Student } \\
\text { Employed }^{*} \\
\text { Unemployed }^{* *} \\
\text { Sex worker } \\
\text { No data }\end{array}$ & $\begin{array}{l}12 \\
2 \\
1 \\
5 \\
2 \\
7\end{array}$ & $\begin{array}{l}(42 \%) \\
(7 \%) \\
(3 \%) \\
(17 \%) \\
(7 \%) \\
(24 \%)\end{array}$ & $\begin{array}{l}38 \\
10 \\
3 \\
1 \\
0 \\
6\end{array}$ & $\begin{array}{l}(66 \%) \\
(17 \%) \\
(5 \%) \\
(2 \%) \\
(0 \%) \\
(10 \%)\end{array}$ \\
\hline Living with a partner & 21 & $(72 \%)$ & 55 & $(95 \%)$ \\
\hline Average parity & 3 & (SD: 2) & 2 & (SD: 1) \\
\hline New pregnancy in 4 years & 18 & $(62 \%)$ & 17 & $(29 \%)$ \\
\hline
\end{tabular}

* Employed: working outside the home.

** Unemployed: not working outside the home.

SD: standard deviation. 
In the EG, $93 \%$ of children visited the emergency department at least once, compared to $79 \%$ in the UG. The main reasons for the visit to the emergency department were respiratory conditions in $55 \%$ of children in the EG and in $26 \%$ of those in the UG $(p<0.001)$. At 4 years old, all children in both groups had completed their immunization schedule.

In addition, 19/29 children $(66 \%)$ in the EG were hospitalized in the Department of Pediatrics, compared to $20 / 58(35 \%)$ in the UG ( $p=0.007)$. A total of 40 hospitalizations were reported in the EG and 23, in the UG. The reasons for hospitalization are shown in Figure 1.

In the 4 years of the study period, 14 children $(48 \%)$ in the EG developed chronic obstructive pulmonary disease; 9/14 were coded as J45 ("asthma") and 5/14, as J44 ("other chronic obstructive pulmonary disease"). No cases were observed in the UG.

\section{Mortality}

In total, 3 violent deaths were reported in the EG in 3 different families over the 4-year study period. One mother died in a motor vehicle collision while driving under the influence of alcohol. One father died due to a stab wound; and one child, due to gunshot wound injuries, both at their homes. No child or parent died in the UG.

\section{Family/legal situation}

In the EG, 8 children (28\%) changed homes (different house and different adult caregiver) in their first 4 years of life (not considering the change required by legal intervention in some cases, which occurred subsequently). Of these 8 children, 3 were relocated twice and 1, 5 times. This meant going to live with a family member other than biological parents or with the friends or neighbors of one of the parents.

One of the biological parents of 8 children in the EG $(28 \%)$ was imprisoned during the 4 years of the study. None of the parents in the UG were in this situation.

In the EG, a legal intervention was requested by the health system for 8 children $(28 \%)$. Four cases corresponded to physical abuse: in 2, the mother had given the child to an unrelated adult; in 1, the mother was imprisoned; and no data were found for the remaining case. Age at

TABLE 4. Delivery and perinatal data of children in the exposed and unexposed groups. Children born at Hospital Molas, La Pampa, between 2009 and 2013

\begin{tabular}{|c|c|c|c|c|}
\hline \multirow{2}{*}{ Type of delivery } & \multicolumn{2}{|c|}{$\begin{array}{l}\text { Exposed group } \\
\quad(n=29)\end{array}$} & \multicolumn{2}{|c|}{$\begin{array}{l}\text { Unexposed group } \\
\quad(\mathrm{n}=58)\end{array}$} \\
\hline & & & & \\
\hline Vaginal & 24 & $(83 \%)$ & 47 & $(81 \%)$ \\
\hline C-section & 5 & $(17 \%)$ & 11 & $(19 \%)$ \\
\hline \multicolumn{5}{|l|}{ Apgar score $<7$} \\
\hline At 1 minute & 2 & $(4 \%)$ & 2 & $(10 \%)$ \\
\hline At 5 minutes & 0 & & 0 & \\
\hline Small for gestational age & 3 & $(10 \%)$ & 1 & $(2 \%)$ \\
\hline Admission to the neonatal intensive care unit & 3 & $(10 \%)$ & 1 & $(2 \%)$ \\
\hline
\end{tabular}

TABLE 5. Comparison of reasons for consultation in the first 4 years of life of children in the exposed and unexposed groups. Children born at Hospital Molas, La Pampa, between 2009 and 2013

\begin{tabular}{lcccc}
\hline & $\begin{array}{c}\text { Exposed group } \\
(\mathbf{n}=\mathbf{2 9 )}\end{array}$ & $\begin{array}{c}\text { Unexposed group } \\
(\mathbf{n}=\mathbf{5 8})\end{array}$ & $\begin{array}{c}\text { Comparison } \\
\text { between groups }\end{array}$ \\
\hline Health checkups & Mean (SD) & $8(6)$ & $18(12)$ & $<0.0001$ \\
Consultations due to & $95 \%$ CI & $6-10$ & $15-22$ & 0.338 \\
concurrent conditions & Mean (SD) & $4(4)$ & $3(3)$ & $3-4$ \\
Visits to the emergency & $95 \% \mathrm{CI}$ & $3-6$ & $3(2)$ & 0.0295 \\
department & Mean (SD) & $5(7)$ & $2-3$ & \\
\end{tabular}

SD: standard deviation; CI: confidence interval. 
the time of the legal intervention ranged from 2 months to 3 years old. No legal interventions were requested in the UG.

At 4 years old, 17 children in the EG were living with their mother $(59 \%) ; 7$ (24\%), with their grandmother; 3 , with foster parents; 1 , with adoptive parents; and 1, no data. In the UG, all children lived with one of their biological parents.

\section{DISCUSSION}

For this study, children in the UG were selected for their similarity in birth weight and gestational age with the children in the EG, because these factors are known to affect infant morbidity and mortality and control requirements, and may be affected by prenatal exposure to any of the substances used by the mothers (tobacco, alcohol, cannabis or cocaine), , $7-13,17,20,21^{-1}$

In addition, we tried to select children for the UG with a similar socioeconomic level to those in the EG: born at the same Department of Neonatology, with the same social security status, maternal age, and close place of residence. The existence of a double control group with a similar socioeconomic level to the EG is the main strength of this study.

Health trajectories of children logically depend on adult caregivers. If no interventions or habit changes take place, drug use and severe social and family risk factors which usually coexist in these families will remain and become part of the rearing environment. ${ }^{12,22}$

In this study, it was not possible to determine whether mothers in the EG continued or not using drugs, although it has been described that postpartum use is very common, even in women who had stopped during pregnancy. ${ }^{23}$

The lower frequency of health checkups in the children in the EG is consistent with a characteristic common to many female drug users, which is attending few or no antenatal care visits. ${ }^{6-9}$ These women have also been commonly described to refuse to participate in investigations, to miss appointments or to drop out, thus making them very troublesome. Therefore, for this study, we opted for a retrospective cohort design using preexisting records, as proposed by other investigators. ${ }^{24}$

The complex nature of illegal drug use during pregnancy also encompasses the coexistence of severe risk factors. For example, mothers of exposed children usually have a mental disease and a history of family violence in their childhood and adulthood. $3,6,8,14$

In this study, among the children in the EG, violence was evidenced in the legal interventions

Figure 1. Reasons why 19/29 children in the exposed group* required 40 hospitalizations and 20/58 children in the unexposed group ${ }^{* *}$ required 23 hospitalizations in the 4 -years study period. ${ }^{* * *}$ Children born at Hospital Molas, La Pampa, between 2009 and 2013

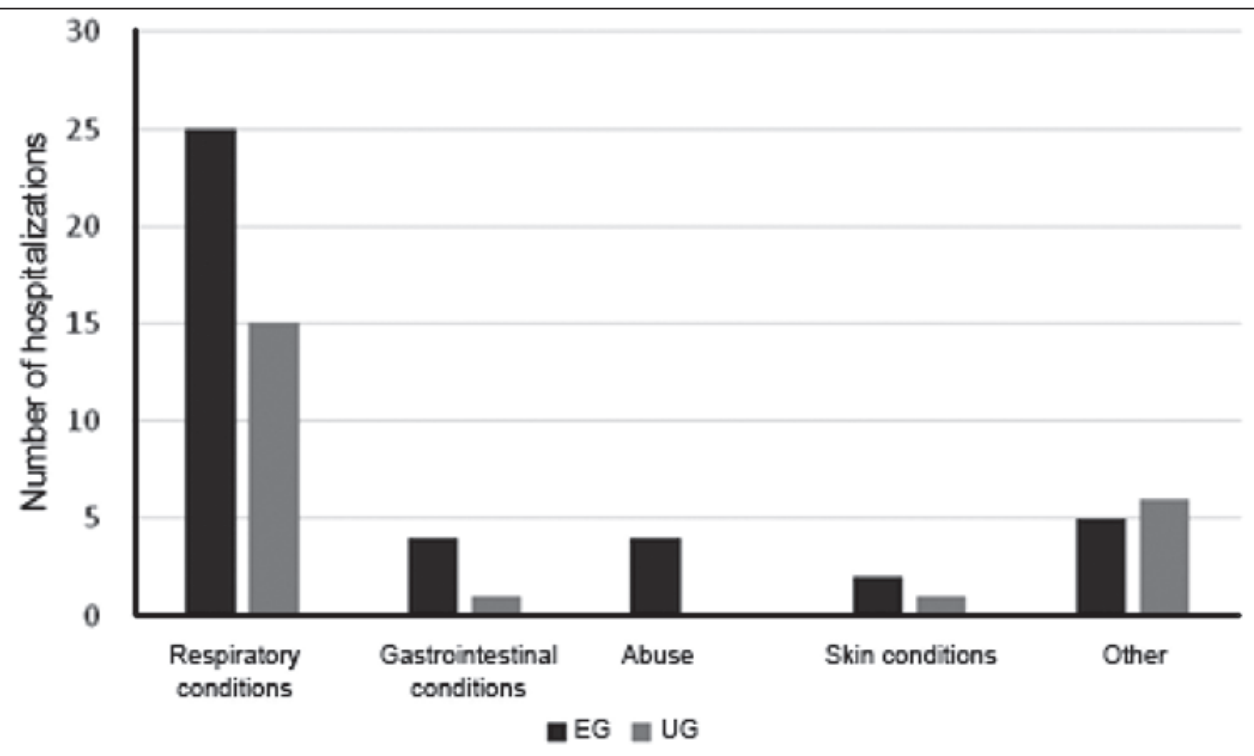

*EG: exposed group; **UG: unexposed group; ${ }^{* * *}$ In both groups, some children required more than 1 hospitalization. 
due to abuse, which has also been observed in other studies, and due to changes in home and adult caregivers. ${ }^{9,13,18,19}$

It is also evidenced in the number of violent deaths of any family member in only 4 years. The latter information had never been described in pediatric studies. In the United States, a higher risk for homicide and violent death has been described in adults and, recently, gun-related homicides among adolescents, in homes where illegal drugs are used. ${ }^{25,26}$

In relation to hospitalizations, it is known that children prenatally exposed to cannabis are more commonly admitted to the neonatal intensive care unit than unexposed ones. . $^{2,610,17,18}$ Among Chilean children exposed mainly to cocaine (although also to tobacco, cannabis, and alcohol, in an unspecified percentage), $60 \%$ required a hospitalization, similar to the $66 \%$ observed in this study. The main reason for hospitalization in both studies corresponded to respiratory conditions. $^{18}$

Likewise, a characteristic of the EG was the high percentage of chronic obstructive pulmonary disease. Most children corresponded to the J45 code (asthma), although it is difficult to establish the diagnosis of asthma before 4 years old. ${ }^{27,28}$

Obstructive respiratory conditions may be caused by different factors, including drug exposure, especially if present in the early stage of life. ${ }^{29}$ Most mothers of children in the EG were poly-drug users.

Tobacco exposure is a known cause for respiratory disease, and the effects resulting from passive smoking have been widely described. ${ }^{29,30}$ It has even been confirmed that prenatal tobacco exposure causes a higher rate of pediatric pulmonary obstruction than postnatal exposure. ${ }^{31,32}$

Cannabis causes chronic bronchitis, and it is known that its main smoke stream carries higher levels of ammonium, hydrogen cyanide, and other toxic chemicals than tobacco smoke. ${ }^{33}$ Some authors have related it to asthma attacks and allergy and a higher number of hospitalizations. ${ }^{34}$

Its effects on the respiratory system due to prenatal exposure are still uncertain, especially due to the high frequency of its use together with tobacco. ${ }^{25,33}$

Five-year-old children prenatally exposed to tobacco and cannabis showed immune alterations of the respiratory mucosa, which may partially account for some respiratory symptoms. ${ }^{35}$

In relation to cocaine, a study conducted in infants younger than 1 year taken to the emergency department found a high frequency of cocaine and a direct correlation between the levels detected and the presence of lower respiratory tract symptoms. ${ }^{36}$

In relation to alcohol, different animal studies have shown that its consumption adversely affects the developing lung. ${ }^{37}$ Some children of women who used alcohol during pregnancy seen at Argentine hospitals had more severe acute respiratory infections than unexposed children, but the effects of prenatal alcohol on chronic obstructive pulmonary disease were controversial. ${ }^{37,38}$

The main limitation of the study design is the need for complete records. In this study, it was not possible to collect data on breastfeeding duration or adequate growth and development.

Although there were no detection criteria (and, therefore, no drug tests done), children in the UG may have been exposed. Such factor may affect results and reduce the differences between groups.

In this study, it was not possible to determine the role of one or other drug, adverse social and family data or pre- or postnatal exposure on the problems observed in children in the EG.

However, the relevance of this study for everyday practice lies in knowing that children with confirmed prenatal exposure to cannabis and / or cocaine have a high risk for morbidity and mortality in the short term. Strategies to approach and follow-up these children should be reformulated considering that they will most likely live in violent settings, with frequent changes of home and a lower attendance to health checkups than unexposed children. Finally, these strategies should focus on both managing drug use and associated social and family risk factors.

\section{CONCLUSIONS}

Children prenatally exposed to cocaine and/or cannabis had a lower number of health checkups and a higher number of visits to the emergency department and hospitalizations. Besides, they showed a greater rate of chronic obstructive pulmonary disease, changes of home, legal interventions, and violent deaths in the direct family group.

\section{REFERENCES}

1. Chang JC, Holland CL, Tarr JA, Rubio D, et al. Perinatal Illicit Drug and Marijuana Use: An Observational Study Examining Prevalence, Screening, and Disclosure. Am J Health Promotion. 2017; 31(1):35-42. 
2. Gunn JKL, Rosales CB, Center KE, Nuñez A, et al. Prenatal exposure to cannabis and maternal and child health outcomes: a systematic review and meta-analysis. BMJ Open. 2016; 6(4):e009986.

3. Rocha PC, Alves MT, Chagas DC, Silva AA, et al. Prevalência e fatores associados ao uso de drogas ilícitas em gestantes da coorte BRISA. Cad SaúdePública. 2016; 32(1):e00192714.

4. Forray A, Foster D. Substance use in the perinatal period. Curr Psychiatry Rep. 2015; 17(11):91.

5. Schauberger CW, Newbury EJ, Colburn JM, Al-Hamadani $\mathrm{M}$. Prevalence of illicit drug use in pregnant women in Wisconsin private practice setting. Am J Obstet Gynecol. 2014; 211(3):255.e1-4.

6. Villarreal M, Ré S. Detección de drogas ilícitas en la orina en el Servicio de Neonatología, Hospital Molas, La Pampa. Arch Argent Pediatr. 2013; 111(3):232-6.

7. Magri R, Míguez H, Parodi V, Hutson J, et al. Consumo de alcohol y otras drogas en embarazadas. ArchPediatrUrug. 2007; 78(2):122-32.

8. García García J, Campistol Mas E, López-Vilchez MÁ, Morcillo Buscato MJ, et al. Análisis del maltrato prenatal en Cataluña entre los años 2011 y 2014. An Pediatr (Barc). 2018; 88(3):150-9.

9. Martín MardomingoM,Solís SánchezG,Málaga GuerreroS, Cuadrillero Quesada C, etal.Consumo de drogas duranteel embarazo y morbilidad neonatal: cambios epidemiológicos en los últimos 10 años. An Pediatr (Barc). 2003; 58(6):574-9.

10. Bonello MR, XuF, Li Z, Burns L, et al. Mental and Behavioral Disorders Due to Substance Abuse and Perinatal Outcomes: A Study Based on Linked Population Data in New South Wales, Australia. Int J Environ Res Public Health. 2014; 11(5):4991-5005.

11. Benevenuto SG, Domenico MD, Martins MA, Costa NS, et al. Recreational use of marijuana during pregnancy and negative gestational and fetal outcomes: An experimental study in mice. Toxicology. 2017; 376:94-101.

12. Behnke M, Smith VC; Committee on Substance Abuse; Committee on Fetus and Newborn. Prenatal substance Abuse:Short- and Long-term Effects on the Exposed Fetus. Pediatrics. 2013; 131(3):e1009-24.

13. Goel N, Beasley D, Rajkumar V, Banerjee S. Perinatal outcome of illicit substance abuse in pregnancycomparative and temporary socio-clinical profile in the UK. Eur J Pediatr. 2011; 170(2):199-205.

14. Minnes S, Lang A, Singer L. Prenatal Tobacco, Marijuana, Stimulant, and Opiate Exposure: Outcomes and Practice Implications. Addict Sci Clinl Pract. 2011; 6(1):57-70.

15. Bandstra ES, Morrow CE, Mansoor E, Accornero VH. Prenatal drug exposure: Infant and toddler outcomes. J Addict Dis. 2010; 29(2):245-58.

16. Lamy $S$, Laqueille $X$, Thibaut F. Conséquences potentielles de la consommation de tabac, de cannabis et de cocaïne par la femme enceinte sur la grossesse, le nouveau-né et l'enfant: revue de littérature. Encephale. 2015; 41(Suppl 1):S13-20.

17. Hayatbakhsh M, Flenady VJ, Gibbons KS, Kingsbury AM, et al. Birth outcomes associated with cannabis use before and during pregnancy. Pediatr Res. 2012; 71(2):215-9.

18. Mena RM, Navarrete MP, Corvalán VS, Bedregal GP. Drogadicción embriofetal por abuso de pasta base de cocaína durante el embarazo. Rev Méd Chile. 2000; 128(10):1093-100.

19. Jaudes PK, Ekwo E, Van Voorhis J. Association of drug abuse and child abuse. Child Abuse Negl. 1995; 19(9):1065-75.

20. Ostrea EM, Ostrea AR, Simpson PM. Mortality within the first 2 years in infants exposed to cocaine, opiate, or cannabinoid during gestation. Pediatrics. 1997; 100(1):7983.
21. Coleman-CowgerVH,OgaE,PetersEN,MarkK.Prevalence and associated birth outcomes of co-use of Cannabis and tobacco cigarettes during pregnancy. Neurotoxicol Teratol. 2018; 68:84-90.

22. SerinoD, Peterson BS, Rosen TS. Psychological Functioning of Women Taking Illicit Drugs during Pregnancy and the Growth and Development of Their Offspring in Early Childhood. J Dual Diagn. 2018; 14(3):158-70.

23. Forray A, Merry B, Lin H, RugerJP, et al. Perinatal Substance Use: A Prospective Evaluation of Abstinence and Relapse. Drug Alcohol Depend. 2015; 150:147-55.

24. Gabrhelík R, Nechanská B, Mravčík V, Skurtveit S, et al. A unique opportunity to Study Short- and Long-Term Consequences in Children Prenatally Exposed to Illicit Drugs and Opioid Maintenance Treatment Using Czech and Scandinavian Registers. Cent Eur J Public Health. 2016; 24(3):248-51.

25. Rivara FP, Mueller BA, Somes G, Mendoza CT, et al. Alcohol and Illicit Drug Abuse and the Risk of Violent Death in the Home. JAMA. 1997; 278(7):569-75.

26. Hohl BC, Wiley S, Wiebe DJ, Culyba AJ, et al. Association of Drug and Alcohol Use With Adolescent Firearm Homicide at Individual, Family, and Neighborhood Levels. JAMA Intern Med. 2017; 177(3):317-24.

27. Pedersen SE, Hurd SS, Lemanske RF Jr, Becker A, et al. Global strategy for the diagnosis and management of asthma in children 5 years and younger. Pediatr Pulmonol. 2011; 46(1):1-17.

28. Klein M. Critique of GINAglobal strategy. Pediatr Pulmonol. 2012; 47(1):99-100.

29. Carraro S, Scheltema N, Bont L, Baraldi E. Early-life origins of chronic respiratory diseases: understanding and promoting healthy ageing. Eur Respir J. 2014; 44(6):168296.

30. McEvoy CT, Spindel ER. Pulmonary effects of maternal smoking on the fetus and child: effects on lung development, respiratory morbidities, and life long lung health. Paediatr Respir Rev. 2016; 21:27-33.

31. Vardavas CI, Hohmann C, Patelarou E, Martinez D, et al. The independent role of prenatal and postnatal exposure to active and passive smoking on the development of early wheeze in children. Eur Respir J. 2016; 48(1):115-24.

32. Neuman A, Hohmann C, Orsini N, Pershagen G, et al. Maternal smoking in pregnancy and asthma in preschool children: a pooled analysis of eight birth cohorts. Am J Respir Crit Care Med. 2012; 186(10):1037-43.

33. Kreuter M, Nowak D, Rüther T, Hoch E, et al. Cannabis--Positionspapier der Deutschen Gesellschaftfür Pneumologie und Beatmungs medizine.V. (DGP). Pneumologie. 2016; 70(2):87-97.

34. Chatkin JM, Zani-Silva L, Ferreira I, Zamel N. CannabisAssociated Asthma and Allergies. Clin Rev Allergy Immunol. 2017; 56(2):196-206.

35. Molnar DS, Granger DA, Shisler S, Eiden RD. Prenatal and postnatal cigarette and cannabis exposure: Effects on Secretory Immunoglobulin A in early childhood. Neurotoxicol Teratol. 2018; 67:31-6.

36. Lustbader AS, Mayes LC, McGee BA, Jatlow P, et al. Incidence of passive exposure to crack/ cocaine and clinical findings in infants seen in an outpatient service. Pediatrics. 1998; 102(1):e5.

37. Gauthier TW, Brown LA. In utero alcohol effects on foetal, neonatal and childhood lung disease. Paediatr Respir Rev. 2016; 21:34-7.

38. Libster R, Ferolla FM, Hijano DR, Acosta PL, et al. Alcohol during pregnancy worsens acute respiratory infections in children. Acta Paediatr. 2015; 104:e494-9. 